\title{
GIÁ TRỊ CỦA CỘNG HƯỞNG TƯ' 3.0 TESLA TRONG CHẨN ĐOÁN CHẤN THƯƠNG ĐÁM RỐI THÂN KINH CÁNH TAY TRƯỚC HACH
}

\author{
Nguyễn Duy Hùng ${ }^{1,2}$ và Nguyễn Thị Xoan ${ }^{1, \square}$ \\ ${ }^{1}$ Trường Đại học Y Hà Nội \\ ${ }^{2}$ Khoa Chẩn đoán hình ảnh, Bệnh viện Hữu nghị Việt Đức
}

Nghiên cứu mô tả cắt ngang từ 3/2016 đến 7/2020 với 66 bệnh nhân có lâm sàng chấn thương đám rối thần kinh cánh tay, được chụp cộng hưởng từ 3.0 Tesla và phẫu thuật thần kinh tại Bệnh viện Hữu nghị Việt Đức và Bệnh viện đa khoa quốc tế Vinmec Times City nhằm mô tả đặc điểm hình ảnh và đánh giá giá trị của cộng hưởng từ 3.0 Tesla trong chẩn đoán chấn thương đám rối thần kinh cánh tay trước hạch. Dấu hiệu chấn thương đám rối thần kinh cánh tay trước hạch trên cộng hưởng từ được mô tả. Giá trị của cộng hưởng từ được phân tích dựa trên sụ̣ so sánh với kết quả phẫu thuật. Các dấu hiệu gián tiếp của tổn thương tủy sống it gặp. Nhổ rễ hoàn toàn và giả thoát vị màng tuỷ có tỷ lệ lần lượt là $52,21 \%$ và 39,39\%, trong đó rễ C7, C8 là vị trí thường gặp. Độ nhạy, độ đặc hiệu, độ chính xác, giá trị chẩn đoán dương tính, giá trị chẩn đoán âm tính của cộng hưởng từ trong chẩn đoán tổn thương trước hạch lần lượt là 68,39\%, 93,14\%, 81,52\%, 89,83\% và $76,89 \%$. Cộng hưởng từ có giá trị trong phát hiện vị trí, mức độ chấn thương trước hạch đám rối thần kinh cánh tay, nên được sử dụng như một phương pháp nhằm cung cấp thêm thông tin trước phẫu thuật.

Từ khóa: Đám rối thần kinh cánh tay, chấn thương, cộng hưởng từ, 3.0 Tesla

\section{I. ĐẠT VẤN ĐỀ}

Chấn thương đám rối thần kinh cánh tay (ĐRTKCT) chỉ gặp 1\% trong đa chấn thương nhưng ảnh hưởng đến chức năng vận động và cảm giác của chi trên, làm giảm chất lượng cuộc sống của bệnh nhân (BN). Chấn thương ĐRTKCT thường gặp ở người trẻ và nguyên nhân chính do tai nạn giao thông. Điều trị và tiên lượng chấn thương ĐRTKCT phụ thuộc vào vị trí, mức độ tổn thương và thời gian từ chấn thương đến phẫu thuật. Chấn thương ĐRTKCT được chia thành tổn thương trước hạch và sau hạch. Mỗi loại tổn thương có

Tác giả liên hệ: Nguyễn Thị Xoan,

Trường Đại học Y Hà Nội

Email: ntxoan.hmu@gmail.com

Ngày nhận: 03/06/2021

Ngày được chấp nhận: 21/07/2021 phương thức phẫu thuật và tiên lượng khác nhau. ${ }^{1}$ Do đó, chẩn đoán đúng giúp đưa đến phẫu thuật kịp thời, làm tăng khả năng phục hồi các triệu chứng thần kinh cho $\mathrm{BN}$.

Chẩn đoán tổn thương ĐRTKCT dựa vào lâm sàng, điện cơ, chẩn đoán hình ảnh. Tuy nhiên, lâm sàng và điện cơ hạn chế trong đánh giá vị trí và mức độ của tổn thương. Cộng hưởng từ $(\mathrm{CHT})$ là phương pháp chẩn đoán hình ảnh không xâm lấn, cung cấp nhiều thông tin hơn siêu âm, điện cơ hay điện thế gợi cảm giác thân thể trong mổ (intraoperative somatosensory evoked potentials) trong đánh giá chấn thương ĐRTKCT. CHT 3.0 Tesla ( $\mathrm{T}$ ) có chỉ số tín hiệu- nhiễu cao hơn các máy $\mathrm{CHT}$ từ trường thấp giúp nâng cao chất lượng hình ảnh trong đánh giá ĐRTKCT. ${ }^{2}$

Trên thế giới, một số nghiên cứu mô tả đặc 
điểm CHT của ĐRTKCT nhưng không sử dụng tiêu chuẩn vàng hoặc so sánh với cắt lớp vi tính tủy cản quang, điện cơ. ${ }^{3}$ Một số nghiên cứu mô tả dấu hiệu chấn thương ĐRTKCT nhưng tiến hành trên máy từ trường thấp. .14-6 Tại Việt Nam, có ít nghiên cứu về chấn thương ĐRTKCT.7,8 Trong nghiên cứu này, chúng tôi tiến hành nghiên cứu đặc điểm hình ảnh của $\mathrm{CHT}$ và giá trị của phương pháp này trong chẩn đoán chấn thương ĐRTKCT trước hạch so sánh với phẫu thuật trên máy CHT 3.0T.

\section{II. ĐÓl TƯỢNG VÀ PHƯƠNG PHÁP}

\section{1. Đối tượng}

BN đưa vào nghiên cứu có tiền sử chấn thương, lâm sàng nghi ngờ chấn thương ĐRTKCT, chụp CHT 3.0T tại khoa Chẩn đoán hình ảnh, Bệnh viện Đa khoa Quốc tế Vinmec Times City và khoa Chẩn đoán hình ảnh bệnh viện Việt Đức, được phẫu thuật tại khoa Phẫu thuật hàm mặt - tạo hình - thẩm mỹ, Bệnh viện Hữu Nghị Việt Đức điều trị tổn thương nhổ rễ, đứt rễ, $u$ thần kinh, tổn thương phù nề mà không cải thiện sau khi theo dõi 3 tháng bằng lâm sàng và điện sinh lý thần kinh, có mô tả chi tiết tổn thương ĐRTKT từ tháng 3/2016 đến 7/2020.

\section{Phương pháp}

Thiết kế nghiên cứu: Nghiên cứu mô tả cắt ngang

Phương pháp chọn mẫu: Chọn mẫu thuận tiện.

Kỹ thuật chụp cộng hưởng từ đám rối thần kinh cánh tay: $\mathrm{BN}$ được chụp $\mathrm{CHT} 3.0 \mathrm{~T}$ trên 02 máy $\mathrm{CHT}$ Siemens MAGNATOM Skyra (Siemens Medical Systems, Erlangen, Germany) và GE SIGNA Pioneer (GE Healthcare, Chicago, IL, USA) với coil cổ- sọ não kèm coil body phủ vùng cổ và vai với người lớn và coil Flex large với trẻ em. $B N$ nằm ngửa, đầu vào trước. Gối và đệm lót được đặt dưới vai và đầu $B N$ nhằm giảm độ cong của cột sống cổ và tạo tư thế thoải mái. $\mathrm{BN}$ được yêu cầu hạn chế nuốt và cử động trong suốt quá trình thăm khám. $\mathrm{BN}$ nằm ngửa, quét theo hướng đầu-chân, từ bờ trên thân đốt sống $\mathrm{C} 3$ đến bờ dưới thân đốt sống $T 3$, từ trước thân đốt sống đến phía sau ống sống, quét cả hai bên nách.

Các chuỗi xung $\mathrm{CHT}$ được sử dụng là: T1W SE (T1 weighted spin echo) coronal: FOV (field of view) $300 \mathrm{~mm}$, bề dày lát cắt $4 \mathrm{~mm}$, TR/TE (repetition time/echo time) 880/11, matrix $512 \times 512$; T2W SE (T1 weighted spin echo) sagittal: FOV $300 \mathrm{~mm}$, bề dày lát cắt 0,8mm, TR/TE 3000/198, matrix 320x384; 3D STIR ( three-dimensional short tau inversion recovery) coronal : FOV $300 \mathrm{~mm}$, bề dày lát cắt $3 \mathrm{~mm}, \mathrm{TR} / \mathrm{TE} 3700 / 85$, matrix $320 \times 384$, CISS (constructive interference steady state)/ FIESTA (fast imaging employing steady state acquisition) coronal: FOV $200 \mathrm{~mm}$, bề dày lát cắt $2 \mathrm{~mm}, \mathrm{TR} / \mathrm{TE} 8,5 / 4$, matrix $320 \times 384$; CISS/ FIESTA axial: FOV $160 \mathrm{~mm}$, bề dày lát cắt $2,5 \mathrm{~mm}, \mathrm{TR} / \mathrm{TE} 9 / 4$, matrix $320 \times 384$. Hình ảnh chuyển lên PACS workstation (Carestream PACS; Carestream Health, Eemnes, Netherlands), dựng MIP (maximum intensity projection) và tái tạo đa mặt phẳng.

Quy trình và phương pháp thu thập số liệu: Thu thập các thông tin về đặc điểm của mẫu nghiên cứu bao gồm các thông tin về tuổi, giới, nguyên nhân và cơ chế chấn thương, tổn thương kèm theo, thời điểm chấn thương, thời điểm chụp $\mathrm{CHT}$, thời điểm phẫu thuật.

Các tổn thương ĐRTKCT do chấn thương được chia làm tổn thương trước hạch và sau hạch dựa vào vị trí hạch gai.9 Dấu hiệu gián tiếp gợi ý tổn thương trước hạch gồm các dấu hiệu tổn thương tủy sống tuy nhiên không đánh giá chính xác vị trí rễ tổn thương. Lệch trục tủy sống là trục tủy sống bị di lệch sang bên đối diện hoặc sang bên tổn thương. ${ }^{2}$ Phù tủy là vùng 
tăng tín hiệu trên T2W gợi ý phù tủy trong giai đoạn cấp. ${ }^{9}$ Chảy máu tủy là tổn thương giảm tín hiệu trên $\mathrm{T} 2 \mathrm{~W}$ gợi ý thành phần hemosidersin sắt lắng đọng sau chảy máu. ${ }^{9}$ Dấu hiệu tổn thương nhổ rễ và màng tủy: nhổ rễ là hình ảnh các rễ con không còn gắn vào tủy sống. Nhổ rễ hoàn toàn khi tất cả rễ con trước và sau bị nhổ ra khỏi tủy sống. ${ }^{9,10}$ Nhổ rễ không hoàn toàn khi chỉ có rễ trước hoặc rễ sau hoặc một số rễ trước và/hoặc một số rễ sau bị nhổ rễ ra khỏi tủy sống. ${ }^{9,10}$ Giả thoát vị màng tủy (GTVMT) là sự mở rộng khoang chứa rễ thần kinh và dịch não tủy vào trong lỗ tiếp hợp, có tín hiệu dịch não tủy; thỉnh thoảng có sự rò rỉ của dịch não tủy vượt quá lỗ tiếp hợp tạo thành cấu trúc dạng nang trong phần mềm cạnh cột sống. . $^{1,9}$ Đặc điểm hình ảnh chấn thương ĐRTKCT trước hạch trên $\mathrm{CHT}$ được mô tả . Phẫu thuật được đặt ra đối với $B N$ có chấn thương cơ chế hở, $\mathrm{BN}$ có tổn thương mất liên tục dây thần kinh hoặc BN không có dấu hiệu phục hồi về lâm sàng và điện cơ sau 3 tháng.

\section{Xử lý số liệu}

Xử lí số liệu bằng phần mềm SPSS 20.0 (Chicago, IL, USA). Các biến số định lượng được mô tả dưới dạng chỉ số trung bình và độ lệch chuẩn nếu có phân bố bình thường, trung vị nếu có phân bố không chuẩn. Đối với các biến định tính được mô tả bằng phần trăm.

\section{4. Đạo đức nghiên cứu}

$\mathrm{BN}$ được giải thích đầy đủ về quy trình nghiên cứu và đồng ý tham gia. Các thông tin hồ sơ bệnh án và hình ảnh đều được chúng tôi bảo mật.

\section{KÉT QUẢ}

\section{1. Đặc điểm chung của đối tượng nghiên cứu}

Nghiên cứu có 66 BN (52 nam, 14 nữ), tuổi trung bình 23 tuổi (0 - 56 tuổi). Nguyên nhân hay gặp nhất là tai nạn giao thông $(75,8 \%)$, tiếp theo là chấn thương sản khoa $(21,2 \%)$. Cơ chế chấn thương kín là $97 \%$, chấn thương hở là $3 \%$. Tổn thương khác đi kèm chiếm $57,6 \%$. Thời gian từ tai nạn đến chụp CHT trung bình là 57 ngày, khoảng dưới 30 ngày là 13,6\%, khoảng từ 30 - 90 ngày là $59,1 \%$. Thời gian từ tai nạn đến phẫu thuật trung bình là 99 ngày, khoảng từ 90 - 180 ngày là $47 \%$, phẫu thuật trong vòng 180 ngày là $83,3 \%$.

\section{2. Đặc điểm hình ảnh tổn thương trước hạch trong chấn thương đám rối thần kinh cánh tay trên CHT 3.0T}

Với các dấu hiệu gián tiếp của tủy sống, di lệch tủy sống gặp trong 8 trường hợp $(12,1 \%)$, phù tủy đều chỉ gặp ở 1 trường hợp, không gặp chảy máu tủy.

\section{Bảng 1. Tổn thương trước hạch}

\begin{tabular}{|c|c|c|c|c|c|c|}
\hline & $\begin{array}{c}\text { C5 } \\
\text { n (\%) }\end{array}$ & $\begin{array}{c}\text { C6 } \\
\text { n (\%) }\end{array}$ & $\begin{array}{c}\text { C7 } \\
\text { n (\%) }\end{array}$ & $\begin{array}{c}\text { C8 } \\
\text { n (\%) }\end{array}$ & $\begin{array}{c}\text { T1 } \\
\text { n (\%) }\end{array}$ & $\begin{array}{l}\text { Tổng } \\
\text { n (\%) }\end{array}$ \\
\hline Nhổ rễ hoàn toàn & $\begin{array}{c}11 \\
4,87\end{array}$ & $\begin{array}{c}19 \\
8,40\end{array}$ & $\begin{array}{c}34 \\
15,04\end{array}$ & $\begin{array}{c}33 \\
14,60\end{array}$ & $\begin{array}{c}21 \\
9,30\end{array}$ & $\begin{array}{c}118 \\
52,21\end{array}$ \\
\hline Nhổ rễ không hoàn toàn & $\begin{array}{c}4 \\
1,77\end{array}$ & $\begin{array}{c}5 \\
2,21\end{array}$ & $\begin{array}{c}6 \\
2,65\end{array}$ & $\begin{array}{c}3 \\
1,33\end{array}$ & $\begin{array}{c}1 \\
0,44\end{array}$ & $\begin{array}{c}19 \\
8,40\end{array}$ \\
\hline GTVMT & $\begin{array}{c}3 \\
1,33\end{array}$ & $\begin{array}{c}11 \\
4,87\end{array}$ & $\begin{array}{c}27 \\
11,95\end{array}$ & $\begin{array}{c}29 \\
12,84\end{array}$ & $\begin{array}{c}19 \\
8,40\end{array}$ & $\begin{array}{c}89 \\
39,39\end{array}$ \\
\hline Tổng & $\begin{array}{c}18 \\
7,97\end{array}$ & $\begin{array}{c}35 \\
15,48\end{array}$ & $\begin{array}{c}67 \\
29,64\end{array}$ & $\begin{array}{c}65 \\
28,77\end{array}$ & $\begin{array}{c}41 \\
18,14\end{array}$ & $\begin{array}{l}226 \\
100\end{array}$ \\
\hline
\end{tabular}


Với tổn thương trước hạch, nhổ rễ và GTVMT là tổn thương thường gặp, tỷ lệ tương ứng là $52,21 \%$ và $39,39 \%$, vị trí thường gặp là rễ $C 7$ và C8. Có $21,22 \%$ có nhổ rễ mà không đi kèm GTVMT.
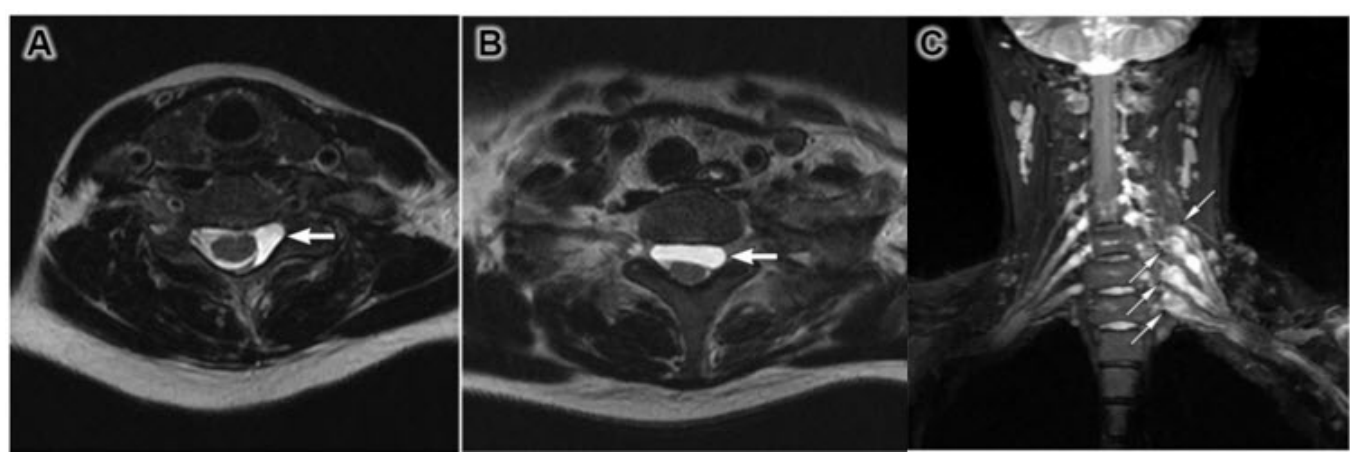

Hình 1. Ảnh chụp CHT của bệnh nhân

BN Trịnh Thị D, nữ, 35 tuổi, mã hồ sơ 59635, tai nạn giao thông xe máy- xe máy cách 3 tháng chụp $\mathrm{CHT}$ có tổn thương nhổ rễ hoàn toàn trước hạch. Chuỗi xung CISS mặt cắt ngang $(\mathrm{A})$ không quan sát thấy hình ảnh rễ con trước và sau bên trái kèm GTVMT ngang mức lỗ tiếp hợp C5/6(mũi tên trắng). Chuỗi xung CISS mặt cắt ngang $(\mathrm{B})$ có hình ảnh GTVMT (mũi tên trắng) nằm phía trước tủy sống ngang mức C6/7 kèm di lệch tủy sống ra sau. Chuỗi xung 3D STIR mặt cắt đứng ngang có dựng hình MIP $(\mathrm{C})$ thấy các rễ $\mathrm{C} 5, \mathrm{C}, \mathrm{C}, \mathrm{C} 8$ co rút ra ngang mức cơ bậc thang (các mũi tên trắng).

3. Giá trị của $\mathrm{CHT}$ 3.0T trong chẩn đoán chấn thương đám rối thần kinh cánh tay trước hạch đối chiếu với phẫu thuật

Bảng 2. Giá trị của CHT 3.0 Tesla trong chẩn đoán tổn thương trước hạch

\begin{tabular}{|c|c|c|c|c|c|c|c|c|c|}
\hline \multirow{2}{*}{\multicolumn{2}{|c|}{$\begin{array}{l}\text { Tổn thương } \\
\text { trước hạch } \\
\text { (nhổ rễ hoàn } \\
\text { toàn) }\end{array}$}} & \multicolumn{2}{|c|}{ PT } & \multirow{2}{*}{$\begin{array}{c}\text { Độ } \\
\text { nhạy } \\
(\%)\end{array}$} & \multirow[b]{2}{*}{$\begin{array}{l}\text { Độ đặc } \\
\text { hiệu (\%) }\end{array}$} & \multirow{2}{*}{$\begin{array}{c}\text { Độ } \\
\text { chính } \\
\text { xác } \\
(\%)\end{array}$} & \multirow{2}{*}{$\begin{array}{l}\text { Giá trị } \\
\text { dụ̣ đoán } \\
\text { dương } \\
\text { tính (\%) }\end{array}$} & \multirow{2}{*}{$\begin{array}{l}\text { Giá trị dụ } \\
\text { đoán âm } \\
\text { tính (\%) }\end{array}$} & \multirow[b]{2}{*}{$\mathbf{P}$} \\
\hline & & Có & Không & & & & & & \\
\hline \multirow{2}{*}{ C5 } & Có & 11 & 0 & \multirow{2}{*}{44,00} & \multirow{2}{*}{100,00} & \multirow{2}{*}{78,79} & \multirow{2}{*}{100,00} & \multirow{2}{*}{74,55} & \multirow{2}{*}{$<0,001$} \\
\hline & Không & 14 & 41 & & & & & & \\
\hline \multirow{2}{*}{ C6 } & Có & 18 & 1 & \multirow{2}{*}{56,25} & \multirow{2}{*}{97,06} & \multirow{2}{*}{77,27} & \multirow{2}{*}{94,74} & \multirow{2}{*}{70,21} & \multirow{2}{*}{$<0,001$} \\
\hline & Không & 14 & 33 & & & & & & \\
\hline \multirow{2}{*}{$\mathrm{C} 7$} & Có & 30 & 4 & \multirow{2}{*}{81,08} & \multirow{2}{*}{86,21} & \multirow{2}{*}{83,33} & \multirow{2}{*}{88,24} & \multirow{2}{*}{78,12} & \multirow{2}{*}{$<0,001$} \\
\hline & Không & 7 & 25 & & & & & & \\
\hline \multirow{2}{*}{ C8 } & Có & 28 & 5 & \multirow{2}{*}{87,50} & \multirow{2}{*}{85,29} & \multirow{2}{*}{86,36} & \multirow{2}{*}{84,85} & \multirow{2}{*}{87,88} & \multirow{2}{*}{$<0,001$} \\
\hline & Không & 4 & 29 & & & & & & \\
\hline \multirow{2}{*}{$\mathrm{T} 1$} & Có & 19 & 2 & 6552 & & & & & \\
\hline & Không & 10 & 35 & 65,52 & 94,59 & 81,82 & 90,48 & 77,78 & $<0,001$ \\
\hline & Có & 106 & 12 & $60 ?$ & 0211 & 0 & 80 & 768 & \\
\hline long & Không & 49 & 163 & 68,39 & 93,14 & 01,02 & 89,03 & 10,89 & \\
\hline
\end{tabular}


Với tổn thương trước hạch, $\mathrm{CHT}$ 3.0T cho giá trị chẩn đoán tổn thương nhổ rễ hoàn toàn với độ nhạy, độ đặc hiệu, độ chính xác, giá trị chẩn đoán dương tính, giá trị chẩn đoán âm tính lần lượt là $68,39 \%, 93,14 \%, 81,52 \%$, $89,83 \%$ và $76,89 \%$, trong đó độ nhạy của rễ C5, C6 thấp hơn rễ C7, C8, T1.

\section{BÀN LUẪN}

Một trong các yếu tố quan trọng giúp phục hồi tối đa thần kinh là thời gian từ chấn thương đến phẫu thuật. Chấn thương hở cần phẫu thuật ngay. Chấn thương kín có nhổ rễ trước hạch hoặc đứt sau hạch cần được phẫu thuật ngay hoặc trong vòng 3 tuần. Khi tổn thương dây thần kinh còn liên tục, nếu $B N$ có gãy xương hoặc bất kì tổn thương cấp tính khác, các tổn thương khác nên được điều trị trước và theo dõi 3 tháng. Nếu tổn thương không hoặc chậm phục hồi, phẫu thuật cần tiến hành trong 6 tháng để tránh sự thoái hóa của dây thần kinh, cơ, bản tận thần kinh. Nghiên cứu của chúng tôi cho thời gian từ chấn thương đến khi phẫu thuật chủ yếu trước 6 tháng. Các nghiên cứu trước đây chưa đưa ra thời điểm cụ thể nên tiến hành chụp $\mathrm{CHT}$. Cắt lớp vi tính tủy cản quang không nên chụp dưới 3 - 4 tuần vì máu trong ống sống gắn vào vị trí màng cứng bị tổn thương có thể làm cho GTVMT không xuất hiện tuy có nhổ rễ. Thời gian từ chấn thương đến chụp $\mathrm{CHT}$ trong nghiên cứu chúng tôi là 57 ngày do $\mathrm{BN}$ có chấn thương khác đi kèm cần ưu tiên điều trị chiếm 57,6\%.

Tổn thương tủy sống trong chấn thương ĐRTKCT trước hạch bao gồm lệch trục tủy sống, phù tủy, chảy máu tủy. Nghiên cứu của Qin trên 33 BN có dấu hiệu di lệch tủy sống gặp trong 16 trường hợp. ${ }^{22}$ Nghiên cứu của Zhang ${ }^{11}$ trên $28 \mathrm{BN}$, tổn thương tủy sống chỉ gặp ở 1 $\mathrm{BN}$ với dấu hiệu phù tủy.Trong nghiên cứu của chúng tôi các dấu hiệu tổn thương tủy sống xuất hiện với tỷ lệ thấp, dấu hiệu di lệch tủy sống là dấu hiệu thường gặp nhất (8/66 BN) có thể gợi ý có tổn thương nhổ rễ trước hạch. Các dấu hiệu tổn thương tủy sống gợi ý nhiều rằng có tổn thương nhổ rễ tuy nhiên không có giá trị trong định vị rễ bị tổn thương. ${ }^{5}$

Các nghiên cứu mô tả đặc điểm hình ảnh của tổn thương trước hạch trong chấn thương ĐRTKCT đã đưa ra các dấu hiệu với tỷ lệ xuất hiện khác nhau. Tác giả Wade nghiên cứu trên máy $\mathrm{CHT} 1.5 \mathrm{~T}$ với $29 \mathrm{BN}$ đã đưa ra đặc điểm nhổ rễ và GTVMT với tỷ lệ lần lượt là $60 \%$ và $40 \%$, thường gặp ở rễ $\mathrm{C} 7$ và C8. ${ }^{1}$ Nghiên cứu của Calvarho với 40 BN trên máy CHT 1.5T cho thấy nhổ hoàn toàn thường gặp ở rễ $\mathrm{C} 7, \mathrm{C} 8$ còn nhổ rễ không hoàn toàn chủ yếu ở rễ C5 và C6 (73,7\% nhổ rễ trước). Nhổ rễ hoàn toàn gặp trong $38,3 \%$ số rễ quan sát trong khi nhổ rễ không hoàn toàn chỉ gặp trong $6,7 \%{ }^{4}{ }^{4}$ Trong nghiên cứu của Arachya ${ }^{6}$ với $33 \mathrm{BN}$ trên máy CHT 1.5T, nhổ rễ và GTVMT có tỷ lệ lần lượt là $56,25 \%$ và $43,57 \%$, thường gặp ở rễ C $7, C 8$, T1. Nghiên cứu của Zhang ${ }^{11}$ với 28 BN trên máy CHT 3.0T lại thấy các dấu hiệu nhổ rễ $42,5 \%$ và $12,5 \%$, thường gặp ở rễ $\mathrm{C} 6, \mathrm{C} 7, \mathrm{C} 8$. Nghiên cứu của Đinh Hoàng Long với 180 rễ (36 BN) trên máy $\mathrm{CHT}$ 1.5T đánh giá hai dấu hiệu tổn thương là GTVMT và nhổ rễ với tỷ lệ lần lượt là $81,1 \%$ và $68,3 \%$, tập trung ở rễ $\mathrm{C} 7, \mathrm{C} 8 .^{7} \mathrm{Tỷ}$ lệ nhổ rễ của tác giả có thể khác do cách tính toán chọn biến dựa trên số rễ tổn thương chứ không dựa trên tổng số tổn thương. Nghiên cứu của Nguyễn Ngọc Trung ${ }^{8}$ cho thấy đối với tổn thương trước hạch thì nhổ rễ và GTVMT có tỷ lệ là $41,7 \%$ và $58,3 \%$, thường gặp ở rễ $C 7$ và C8.Nghiên cứu của chúng tôi cho kết quả tương tự với tỷ lệ nhổ rễ và GTVMT lần lượt là $60,61 \%$ và $39,39 \%$, thường gặp ở rễ $\mathrm{C} 7, \mathrm{C} 8$. Do cấu tạo của rễ $\mathrm{C} 7, \mathrm{C} 8$ không có dây chằng dính rễ thần kinh vào lỗ tiếp hợp tương tự như ở rễ C5, C6 nên dễ bị tổn thương nhổ rễ. 
Trong nghiên cứu của chúng tôi có 21,21\% tổn thương nhổ rễ mà không có GTVMT đi kèm, tương đồng với các nghiên cứu khác. ${ }^{1}$ Một số tác giả cho rằng GTVMT không phải là dấu hiệu tin cậy của nhổ rễ do tỷ lệ dương tính giả có thể tới 15 - 20\%, GTVMT có thể do tổn thương gây co kéo màng tủy và thoát dịch não tủy ra ngoài mà không có tổn thương nhổ rễ. ${ }^{1}$ Tuy nhiên, với tỉ lệ xuất hiện GTVMT cao trong tổn thương trước hạch, GTVMT nên được xem là chỉ điểm tốt cho tổn thương nhổ rễ trước hạch. ${ }^{6}$

Các nghiên cứu về giá trị của $\mathrm{CHT}$ trong chẩn đoán tổn thương nhổ rễ có số lượng $\mathrm{BN}$, lựa chọn biến số và thực hiện trên các máy $\mathrm{CHT}$ có từ trường khác nhau, vì vậy kết quả nghiên cứu không đồng nhất. Nghiên cứu hệ thống của Wade về giá trị của $\mathrm{CHT}$ trên các máy từ $0.5 \mathrm{~T}$ đến $3 T$ trong chẩn đoán tổn thương nhổ rễ đã cho độ nhạy 77 - 98\%, độ đặc hiệu 42 - 90\% và chỉ ra các máy $\mathrm{CHT}$ từ trường cao như 3.0T giúp tăng độ nhạy và giảm độ đặc hiệu. ${ }^{12}$ Một nghiên cứu khác của Wade với 29 BN trên máy CHT 1.5T có đối chiếu phẫu thuật cho thấy tổn thương nhổ rễ có độ nhạy, độ đặc hiệu, độ chính xác, giá trị chẩn đoán dương tính, giá trị chẩn đoán âm tính lần lượt là 68\%, 85\%,79\%,75\%, $81 \%$ còn tổn thương GTVMT lần lượt là $40 \%$, 87\%, 68\%,65\%,69\%. ${ }^{1}$ Theo nghiên cứu của Zhang trên máy CHT 3.0T có đối chiếu phẫu thuật, độ nhạy, độ đặc hiệu, độ chính xác, giá trị dự đoán âm tính, giá trị dự đoán dương tính lần lượt là 93,55\%, 71,43\%, 89,47\%, 93,50\%, $71,43 \% .^{11}$ Nghiên cứu của Acharya trên máy CHT 1.5T khi so sánh với phẫu thuật cho độ nhạy, độ đặc hiệu, độ chính xác, giá trị dự đoán dương tính và âm tính của tổn thương nhổ rễ là 39\%, 75\%, 51\%, 75\%, 39\% với độ nhạy ở rễ C5, C6 thấp (tương ứng 31,58\% và 46,15\%). ${ }^{6}$ Nghiên cứu của chúng tôi trên cả người lớn và trẻ em cho kết quả gần tương đồng với các nghiên cứu trước với độ nhạy, độ đặc hiệu, độ chính xác, giá trị dự đoán dương tính và âm tính lần lượt 68,39\%, 93,14\%, 81,52\%, 89,83\% và 76,89\%. Độ nhạy trong đánh giá nhổ rễ ở rễ C5 và C6 thấp do khoang dưới nhện ngang mức C5, C6 hẹp và góc chếch của rễ con tại các rễ này gây khó khăn trong kỹ thuật. ${ }^{6}$ Khi có chấn thương, $\mathrm{BN}$ thường khó nằm yên nên đối với $\mathrm{CHT}$ từ trường cao rất nhạy với chuyển động dễ gây ra nhiễu ảnh, đặc biệt là ở các rễ có khoang dưới nhện hẹp. Sự khác biệt so với nghiên cứu của Zhang do sư khác biệt về cỡ mẫu, nghiên cứu của chúng tôi có $66 \mathrm{BN}$ trong khi nghiên cứu của Zhang chỉ có 28 BN. Nghiên cứu của Zhang ${ }^{11}$ đánh giá giá trị dựa vào tất cả các dấu hiệu trước hạch để tính giá trị, chúng tôi chỉ đánh giá dấu hiệu nhổ rễ hoàn toàn. Nghiên cứu của Qin² trên 33 BN ở máy CHT 3.0T so sánh với phẫu thuật có điện cơ hoặc đưa ra kết quả độ nhạy, độ đặc hiệu, độ chính xác khi đánh giá chung tất cả các dấu hiệu tổn thương trước hạch với lần lượt là $96,8 \%$, $57,1 \%, 94,1 \% 2$, khác biệt với chúng tôi chỉ đánh giá tổn thương nhổ rễ hoàn toàn.Nghiên cứu của Nguyễn Ngọc Trung ${ }^{8}$ trên 60 BN ở máy $\mathrm{CHT}$ 1.5T cho tỷ lệ chẩn đoán đúng số lượng rễ bị nhổ trên ảnh CHT so với phẫu thuật là 86,2\% tương đương với nghiên cứu của chúng tôi.

Tổn thương chấn thương ĐRTCT trước hạch đã được nghiên cứu trên các phương pháp như chụp cắt lớp vi tính tủy cản quang và $\mathrm{CHT}$. Độ nhạy và độ đặc hiệu của cắt lớp vi tính tủy cản quang trong chẩn đoán nhổ rễ khi so sánh với phẫu thuật trong nghiên cứu của Doi tương ứng là $90 \%$ và $80 \% .^{13}$ Nghiên cứu của Bordalo-Rodrigues trên $52 \mathrm{BN}$ có chụp cắt lớp vi tính tủy cản quang trên máy 64 dãy và $\mathrm{CHT}$ 1.5T cho kết quả độ nhạy và độ chính xác của cắt lớp vi tính tủy cản quang trong chẩn đoán nhổ rễ là $71,7 \%$ và $75,4 \% .{ }^{14} \mathrm{CHT}$ là phương pháp không xâm lấn, với độ đặc hiệu tương đương tuy độ nhạy của cắt lớp vi tính tủy cản 
quang cao hơn.

Nghiên cứu của chúng tôi cho thấy độ nhạy của CHT không cao do còn một số hạn chế. Thời gian chụp cộng hưởng từ ĐRTKCT còn kéo dài có thể gây ra khó chịu cho bệnh nhân tạo ra nhiễu ảnh cử động hoặc hô hấp. Ngoài ra, nghiên cứu của chúng thực hiện tại 1 trung tâm phẫu thuật và 2 trung tâm chẩn đoán hình ảnh nên tính đại diện là chưa cao. Thời gian từ lúc chụp $\mathrm{CHT}$ đến lúc phẫu thuật còn tương đối xa nhau. Để đưa ra phương pháp điều trị tốt nhất cho $\mathrm{BN}$ cần phối hợp giữa bộ ba chẩn đoán bao gồm lâm sàng, chẩn đoán hình ảnh, điện cơ. Đối với $\mathrm{CHT}$, để nâng cao khả năng chẩn đoán chính xác cần chọn thời điểm chụp phim thích hợp, có phối hợp thêm thuốc chống phù nề, thuốc giảm đau cho BN để hạn chế nhiễu ảnh.

\section{KÉT LUÂN}

Cộng hưởng từ 3.0T có giá trị trong phát hiện vị trí, đánh giá hình thái và mức độ chấn thương trước hạch của đám rối thần kinh cánh tay. Độ đặc hiệu của phương pháp này là tốt, tuy độ nhạy không cao, cộng hưởng từ 3.0T nên được sử dụng như một phương pháp nhằm cung cấp thêm thông tin trước phẫu thuật.

\section{TÀI LIẸU THAM KHẢO}

1. Wade RG, Itte V, Rankine JJ, Ridgway JP, Bourke G. The diagnostic accuracy of 1.5T magnetic resonance imaging for detecting root avulsions in traumatic adult brachial plexus injuries. J Hand Surg Eur Vol. 2018;43(3):250258. doi:10.1177/1753193417729587

2. Qin B-G, Yang J-T, Yang $Y$, et al. Diagnostic Value and Surgical Implications of the 3D DW-SSFP MRI On the Management of Patients with Brachial Plexus Injuries. Sci Rep. 2016;6(1). doi:10.1038/srep35999

3. Qiu TM, Chen L, Mao Y, et al. Sensorimotor cortical changes assessed with resting- state fMRI following total brachial plexus root avulsion. J Neurol Neurosurg Psychiatry. 2014; 85(1): 99-105. doi:10.1136/jnnp-2013-304956

4. Carvalho GA, Nikkhah G, Matthies C, Penkert G, Samii M. Diagnosis of root avulsions in traumatic brachial plexus injuries: value of computerized tomography myelography and magnetic resonance imaging. J Neurosurg. 1997; 86(1): 69-76. doi:10.3171/ jns. 1997.86.1.0069

5. Hems TEJ, Birch R, Carlstedt T. The Role of Magnetic Resonance Imaging in the Management of Traction Injuries to the Adult Brachial Plexus. J Hand Surg. 1999; 24(5): 550-555. doi:10.1054/JHSB.1999.0234

6. Acharya AM, Cherian BS, Bhat AK. Diagnostic accuracy of MRI for traumatic adult brachial plexus injury: A comparison study with surgical findings. J Orthop. 2020; 17:53-58. doi:10.1016/j.jor.2019.08.015

7. Đinh Hoàng Long. Hình ảnh tổn thương đám rối thần kinh cánh tay trên cộng hưởng từ 1,5 Tesla. Luận văn Bác sỹ chuyên khoa cấp II, Viện nghiên cứu khoa học Y Dược lâm sàng 108. 2012: 55-104.

8. Nguyễn Ngọc Trung. Nghiên cứu đặc điểm hình ảnh và giá trị của cộng hưởng từ trong chẩn đoán tổn thương đám rối thần kinh cánh tay do chấn thương. Luận văn Tiến sỹ $Y$ học, Viện nghiên cứu khoa học Y Dược lâm sàng 108. 2019:54-125.

9. Caranci F, Briganti F, La Porta M, et al. Magnetic resonance imaging in brachial plexus injury. Musculoskelet Surg. 2013; 97(S2):181190. doi:10.1007/s12306-013-0281-0

10. Silbermann-Hoffman O, Teboul F. Posttraumatic brachial plexus $\mathrm{MRI}$ in practice. Diagn Interv Imaging. 2013; 94(10): 925-943. doi:10.1016/j.diii.2013.08.013

11. Zhang L, Xiao T, Yu Q, Li Y, Shen F, Li W. Clinical Value and Diagnostic Accuracy of 3.0T 
Multi-Parameter Magnetic Resonance Imaging in Traumatic Brachial Plexus Injury. Med Sci Monit Int Med J Exp Clin Res. 2018; 24:71997205. doi:10.12659/MSM.907019

12. Wade RG, Takwoingi Y, Wormald JCR, et al. Magnetic resonance imaging for detecting root avulsions in traumatic adult brachial plexus injuries: protocol for a systematic review of diagnostic accuracy. Syst Rev. 2018;7(1). doi:10.1186/s13643-018-0737-2

13. Doi K, Otsuka K, Okamoto $Y$, Fujii $\mathrm{H}$, Hattori $\mathrm{Y}$, Baliarsing AS. Cervical nerve root avulsion in brachial plexus injuries: magnetic resonance imaging classification and comparison with myelography and computerized tomography myelography. J Neurosurg. 2002;96(3 Suppl):277-284.

14. Bordalo-Rodrigues $M$, Siqueira MG, Kurimori CO, et al. Diagnostic accuracy of imaging studies for diagnosing root avulsions in post-traumatic upper brachial plexus traction injuries in adults. Acta Neurochir (Wien). Published online June 26, 2020. doi:10.1007/ s00701-020-04465-9

\section{Summary}

\section{VALUE OF 3.0 TESLA MAGNETIC RESONACE IMAGING IN ASSESSING PREGANGLIONIC TRAUMATIC BRACHIAL PLEXUS INJURY}

A cross-sectional study was performed on 66 patients who had clinical manifestations of BPI, underwent 3.0 Tesla MRI of the brachial plexus and were treated by nerve surgery at VietDuc University and Vinmec Times City internaltional hospitals, Ha Noi, Viet Nam from March 2016 to July 2020. The objectives are to describe the characteristic features and determining the diagnostic accuracy of 3.0 Tesla magnetic resonance imaging (MRI) in assessing preganglionic brachial plexus injury (BPI) compared to the intraoperative findings. The features of preganglionic lesions on MRI were described. The diagnostic accuracy of MRI in assessing BPI was analyzed based on the intraoperative findings. The rate of total avulsion and pseudomeningocele were $52.21 \%$ and $39.39 \%$, respectively, in which $\mathrm{C} 7$ and C8 nerve roots were the common location of injury. The sensitivity, specificity, accuracy, positive prognostic value and negative prognostic value of MRI for preganglionic injury were $68.39 \%, 93.14 \%, 81.52 \%, 89.83 \%$ and $76.89 \%$, respectively. In conclusion, MRI was useful in detecting preoperatively the location and the injured degree of injury of traumatic brachial plexus. It should be used as a preoperative supplemental investigation tool.

Keywords: Brachial plexus, trauma, MRI, 3.0 Tesla. 